\title{
Hypoxic isolated abdominal perfusion breaks through chemoresistance in recurrent FIGO stage IIIC and IV ovarian cancer
}

\author{
KARL R. AIGNER, SABINE GAILHOFER and KORNELIA AIGNER \\ Department of Surgical Oncology, Medias Klinikum Burghausen, D-84489 Burghausen, Germany
}

Received July 14, 2020; Accepted April 9, 2021

DOI: $10.3892 / \mathrm{mco} .2021 .2291$

\begin{abstract}
To overcome drug resistance in relapsed ovarian cancer, an isolated perfusion system was used to generate a higher local exposure to cytostatic drugs. In addition to cisplatin as the cytostatic agent of choice, the present study combined adriamycin and mitomycin in a three drugs regime due to their increased cytotoxicity under hypoxia. A total of 107 patients, including 87 patients with relapses after previous platinum-containing therapies, 46 stage IIIC and 41 stage IV cases, were enrolled in the present study. A total of 25 patients were chemonaive, including 20 stage IIIC. The systemically pretreated patients in stage IIIC survived a median of 12.8 months, and those in stage IV 10.9 months. The overall clinical response rate of stages IIIC and IV combined was $69 \%$. A complete decrease in ascites was found in $43 \%$ of all patients, a significant reduction in $19 \%$. Toxicity and side effects were very mild and the bone marrow suppression was mostly grade I and never exceeded grade II. The primary clinical symptom in patients with post-therapeutic tumor necrosis, which occurred in $10-15 \%$ of all cases, was fever, fatigue and poor performance. The isolated hypoxic abdominal perfusion treatment is a potent instrument to break an existing chemoresistance without significant side effects with a good quality of life and comparatively long survival time.
\end{abstract}

Correspondence to: Professor Karl R. Aigner, Department of Surgical Oncology, Medias Klinikum Burghausen, Krankenhausstr. 3a, D-84489 Burghausen, Germany

E-mail: info@medias-klinikum.de

Abbreviations: ECOG, Eastern Cooperative Oncology Group; CT, computed tomography; FIGO, Fédération Internationale de Gynécologie et d'Obstétrique; CA, carbohydrate antigen; PFS, progression-free survival; WHO, World Health Organization; OS, overall survival; LDH, lactate dehydrogenase; PCS, primary cytoreductive surgery; NACT, neoadjuvant chemotherapy; HIPEC, hyperthermic intraperitoneal chemotherapy; AUC, area under the curve; RCT, regional chemotherapy

Key words: isolated perfusion, ovarian cancer, quality of life, chemoresistance, platin-refractory tumors, hypoxic abdominal perfusion, recurrent ovarian cancer, intraarterial chemotherapy

\section{Introduction}

Clinical research has noticeably improved progression-free survival and overall survival over the past few decades. Nevertheless, ovarian cancer is still the leading cause of death among all gynecological malignancies. The insidiousness of the disease is the early peritoneal spread, the rapid development of chemoresistance and the bypassing of the hosts immune response (1). The recommended therapy option is complete surgical cytoreduction and chemotherapy with a combination carboplatin and taxanes (2-4). Although a complete remission rate of $\sim 80 \%$ is achieved, platinum-resistance often occurs within two years. The shorter the relapse-free interval, the less likely the tumor will respond again (5-7). A higher individual dose or dose-dense therapy could induce a new response, but are incompatible and too toxic for the patient (8-13). Even modified drug combinations or high-dose chemotherapy have not brought any real progress (14-17). Hyperthermic intraperitoneal chemotherapy has been of recent interest, particularly after surgical cytoreduction (18-20). Alternatively, new drugs or targeted substances can be considered (21-24). Because of responsiveness increases with an increased dose or concentration of cytostatics, we assume that isolated perfusion in a closed circuit is able to break through chemoresistance due to the increased exposure to cytostatic drugs.

In order to keep the systemic toxicity within acceptable limits, and to maintain the quality of life, chemofiltration was carried out directly after the therapy $(25,26)$. We herein present a cohort study of 107 patients who underwent hypoxic abdominal perfusion. All pretreated patients had recurrent stage IIIC and IV epithelial ovarian cancers resistant to platinum-containing drug combinations.

\section{Materials and methods}

Patients. The study included 107 patients in the FIGO stages IIIC and IV, who were treated in one institution between 1997 and 2017. 87 patients were previously treated with platinum-containing combination chemotherapies, mostly taxanes and had recurrent epithelial ovarian cancers, resistant to platinum-based drug combination. 46 patients were stage FIGO IIIC and 41 were stage IV. An additional 20 patients who had refused prior therapies were all stage IIIC. 34 patients had G3 degree malignancies (Table I). All pretreated patients had 
received at least two prior lines of chemotherapy. 7 had undergone third-line and one patient fourth-line therapies. The median platinum-free interval in 46 stage IIIC patients was 7 months and in 41 patients in stage IV was 9 months (Table II). Performance status was mostly stage ECOG 2 and 3 . The 20 patients who had refused prior systemic chemotherapy received the same isolated perfusion therapy as the 87 patients with recurrent disease. The possibility of debulking surgery after diagnosis of progression was not considered feasible in terms of patient's performance and advanced disease in all cases.

Investigations were performed in compliance with the principles of good clinical practice outlined in the Declaration of Helsinki and federal guidelines, and had approval by the Medias Institutional Review Committee. Informed consent was obtained from each participant or participant's guardian. Patients were required to have an ECOG performance status of 3 or less. Exclusion criteria included cardiovascular disease, uncontrolled diabetes and serious infections. The white blood count had to be no less than 2,500/ $\mu 1$, and should under no circumstances be in decline before starting therapy. The same applied to the platelet count with a limit of no less than 100,000/ $\mu 1$.

Isolated hypoxic abdominal perfusion. The procedure (Fig. 1) is carried out with heparinization at $150 \mathrm{IU} / \mathrm{kg}$ body weight under general anesthesia and takes a total of one and a half to two hours. The femoral vessels, artery and vein, are exposed through a short incision in the groin and cannulated with stop-flow balloon catheters (Dispomedica, Hamburg). Both thighs are blocked with inflatable pneumatic cuffs. The venous balloon is positioned in the vena cava between the confluence of the hepatic vein and the right atrium, the aortic balloon shortly above the diaphragm level. After the correct position of the balloons has been documented with contrast medium, they are unblocked again and after temporary hyperoxygenation, the cytostatic combination is injected as a bolus into the aorta and both balloons are blocked again immediately. To prevent an initial acidification of the system, the balloons are only blocked after a short prior hyperoxygenation and aortic bolus injection of the chemotherapeutic agents. The therapy itself is conducted for 15 min under hypoxic conditions. Mitomycin and adriamycin unlike other cytostatics exhibit an augmented tumoricidal effect under hypoxia. The $\mathrm{pH}$ value has no influence on the efficacy of cisplatin (27). In isolated hypoxic abdominal perfusion the average dose of cisplatin was $60 \mathrm{mg}$, the maximum safe intra-arterial total dose of cisplatin was $70 \mathrm{mg}$ as a bolus-injection. The maximum dose of adriamycin was $50 \mathrm{mg}$ and for mitomycin $20 \mathrm{mg}$ totally at one shot into the aorta. These seemingly low doses of cisplatin and adriamycin develop high active concentrations when used intra-arterially in an isolated circuit. Due to the intra-arterial application, the chemotherapeutics were not dosed by bodyweight for these patients. Plasma levels of mitomycin and adriamycin are 50 times higher in the arterial vs. venous perfusion line for the first three minutes and then adjust (28). Leakage monitoring is not necessary during the $15 \mathrm{~min}$ isolated perfusion period because after the balloons and thigh pressure cuffs have been unblocked, chemofiltration via the perfusion catheters is started immediately. Chemofiltration is continued at a maximum blood flow rate of $500 \mathrm{ml}$ per minute to a substitution volume of 4 liters. After completing chemofiltration, the catheters are removed and the vessels repaired with running sutures.
Table I. Patient characteristics $(\mathrm{n}=107)$.

Value

Variable

Pretreated $(\mathrm{n}=87)$ Non-pretreated $(\mathrm{n}=20)$

\begin{tabular}{lcc}
\hline $\begin{array}{l}\text { Median age, years } \\
\text { Stage, } \mathrm{n}(\%)\end{array}$ & 56.6 & \\
FIGO IIIC & $46(53)$ & $0(100)$ \\
FIGO IV & $41(47)$ & $0(0)$ \\
Grading, n (\%) & $34(30)$ & \\
G3 & &
\end{tabular}

FIGO, Fédération Internationale de Gynécologie et d'Obstétrique.

Table II. Time interval between prior treatments and hypoxic abdominal perfusion with chemofiltration.

\begin{tabular}{lcc}
\hline Stage & No. & $\begin{array}{c}\text { Median platinum-free } \\
\text { interval before perfusion }\end{array}$ \\
\hline FIGO IIIC non-pretreated & 20 & No pretreatment \\
FIGO IIIC pretreated & 46 & 7 months \\
FIGO IV pretreated & 41 & 9 months
\end{tabular}

FIGO, Fédération Internationale de Gynécologie et d'Obstétrique.

The isolated hypoxic abdominal perfusion is conducted in four cycles in three to four weeks intervals each. The blood count is checked weekly, and, while approaching the lowest Nadir, controls are carried out every second day until the blood count starts to reemerge. The tumor marker CA12-5 is checked before each therapy and a CT monitoring was performed two weeks after the second and fourth perfusion each. The extent of the residual tumor load and the tumor response were assessed according to the course of the tumor marker, the amount of residual ascites and the CT findings as well as the general condition of the patient. In case of progressive peritoneal lesions or distant metastases the treatment was discontinued.

Statistical analysis. Statistics have been calculated with $95 \%$ confidence limits. Survival times were estimated using the Kaplan-Meier product limit estimator and follow up for the surviving patients was minimum 12 months. Statistical analyses were performed using MediasStat software, version 28.5.14.

\section{Results}

Endpoints of the study. The most important endpoints of the trial were quality of life and overall survival, followed by the response rates. The latter was derived from the clinical response rate in the form of the tumor marker CA 12-5, the computer tomographic control and not least, quality of life.

Quality of life (QoL). QoL was in particular measured in the form of the decline or complete disappearance of ascites and especially, the substantial improvement in pain and the often described 
Table III. Response rates of pretreated Fédération Internationale de Gynécologie et d'Obstétrique stage IIIC and IV patients with recurrent disease.

\begin{tabular}{lcccr}
\hline Response & Stage IIIC, $\%$ & Stage IV, $\%$ & Stage IIIC/IV, $\%$ & Ascites, $\%$ \\
\hline PD & 6.5 & 9.8 & 8.0 & 0.0 \\
SD & 26.1 & 19.5 & 23.0 & 0.0 \\
PR & 47.8 & 56.1 & 51.7 & 19.0 \\
CR & 19.6 & 14.6 & 17.3 & 43.0 \\
CR+PR & 67.4 & 70.7 & 69.0 & 62.0 \\
\hline
\end{tabular}

$\mathrm{PD}$, progressive disease; $\mathrm{SD}$, stable disease; $\mathrm{CR}$, complete response; $\mathrm{PR}$, partial response.

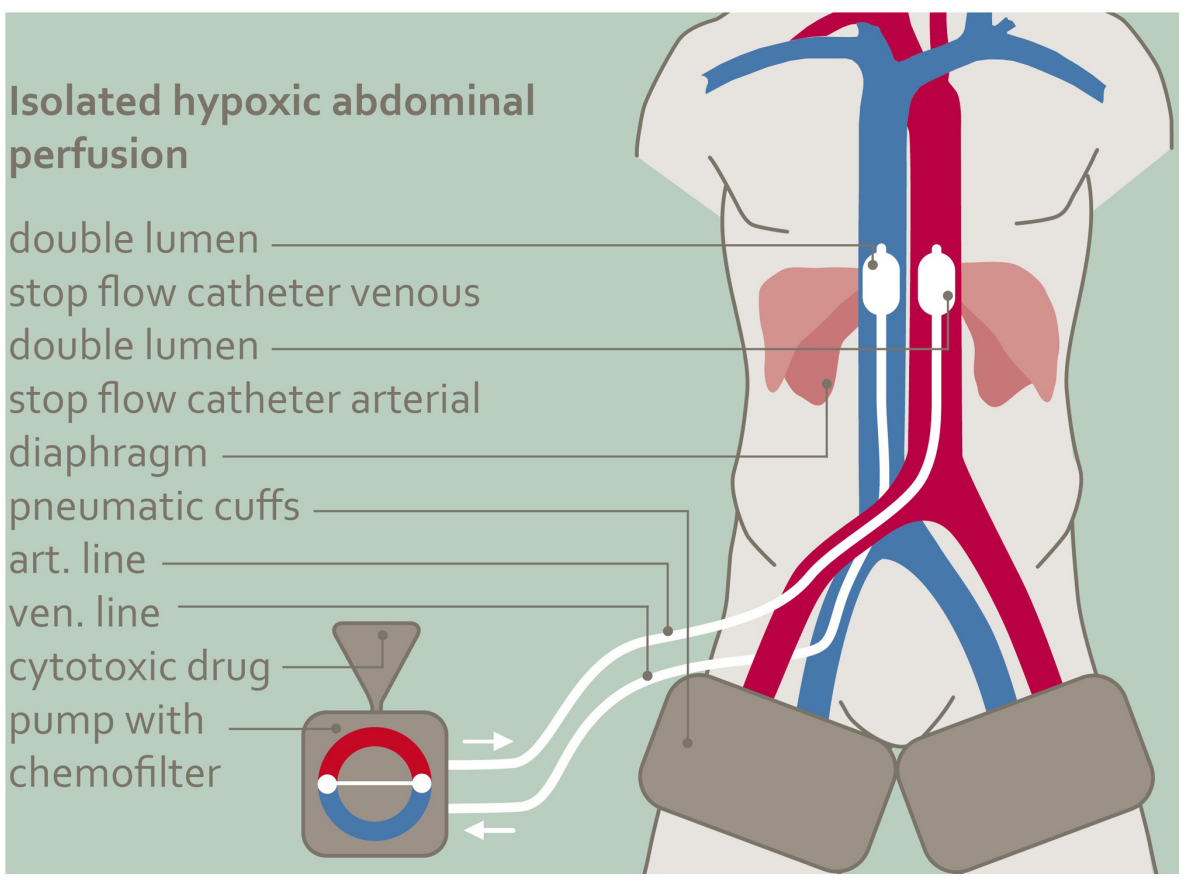

Figure 1. Schematic of isolated hypoxic abdominal perfusion through cannulation of the femoral artery and vein. The balloon catheters are positioned beneath the diaphragm and connected with an extracorporeal roller pump. Art., arterial; ven., venous.

general discomfort. Patients who had prior systemic followed by regional chemotherapy filled in questionnaires comparing the intensity of the most common side effects after the respective therapies in a scale from one to six. Patients perceived regional perfusion therapy less stressing than conventional chemotherapy.

Response rates. A positive influence on clinical response rates was noted among $69 \%$ of all patients in stage IIIC and IV. The rate of complete remissions was $19,6 \%$ in stage IIIC and $14,6 \%$ in stage IV, partial remissions 47,8 and $56,1 \%$ respectively. Complete disappearance of ascites was observed in $43 \%$ of patients after only two perfusions, and $19 \%$ of patients reported a $50 \%$ or more reduction of abdominal pressure and fluid volume (Table III). A considerable improvement in general wellbeing, with a reduction in abdominal symptoms and a substantial decrease in pain, was reported by $74 \%$ or $3 / 4$ of patients with advanced ovarian carcinoma.

Survival. The median progression-free survival (PFS) of all 87 patients was 8 months, the median overall survival
11.9 months (Fig. 2). The median survival rate of pretreated platinum-refractory patients at FIGO IIIC stage was 12.8 months and at stage IV, 10.9 months (Fig. 3). In stage IIIC, overall survival in pretreated vs. non-pretreated patients at one year is 54 vs. $70 \%$, respectively, at two years 25 vs. $40 \%$ at three years 19 vs. $30 \%$, and at four years still 13 vs. $25 \%$ (Fig. 4). The response rates are summarized in Table III. The annual survival rates of 1-4 years for all patients together and selectively at FIGO IIIC and IV stage are summarized in Table IV.

Toxicity. Bone marrow depression ranged between WHO grade 1 and 2. Only patients with a reduced bone marrow reserve after stressful third and fourth-line therapy had leucopenia and thrombocytopenia grade 3 even after perfusion therapy with chemofiltration. WHO grade 4 toxicity and neutropenic fever as well as neuropathy in terms of hand-foot-syndrome were never observed. In the event of rapid tumor necrosis, which can occur during the first three post-therapeutic days, the patient report tiredness and fatigue with a simultaneous increase in LDH and tumor marker, which falls below the initial value 
Table IV. Annual survival rates of 1-4 years of all pretreated FIGO stage IIIC and IV patients ( $\mathrm{n}=87$ ) with recurrent disease.

\begin{tabular}{lccccc}
\hline Stage & 1-year OS, $\%$ & 2-year OS, $\%$ & 3-year OS, $\%$ & 4-year OS, $\%$ & 13-year OS, $\%$ \\
\hline FIGO IIIC/IV (n=87) & 47.1 & 23.8 & 16.4 & 9.8 & - \\
FIGO IIIC $(\mathrm{n}=46)$ & 54.3 & 25.2 & 19.2 & 12.8 & 3.1 \\
FIGO IV (n=41) & 39.0 & 22.0 & 13.2 & 9.5 & - \\
\hline
\end{tabular}

FIGO, Fédération Internationale de Gynécologie et d'Obstétrique; OS, overall survival.

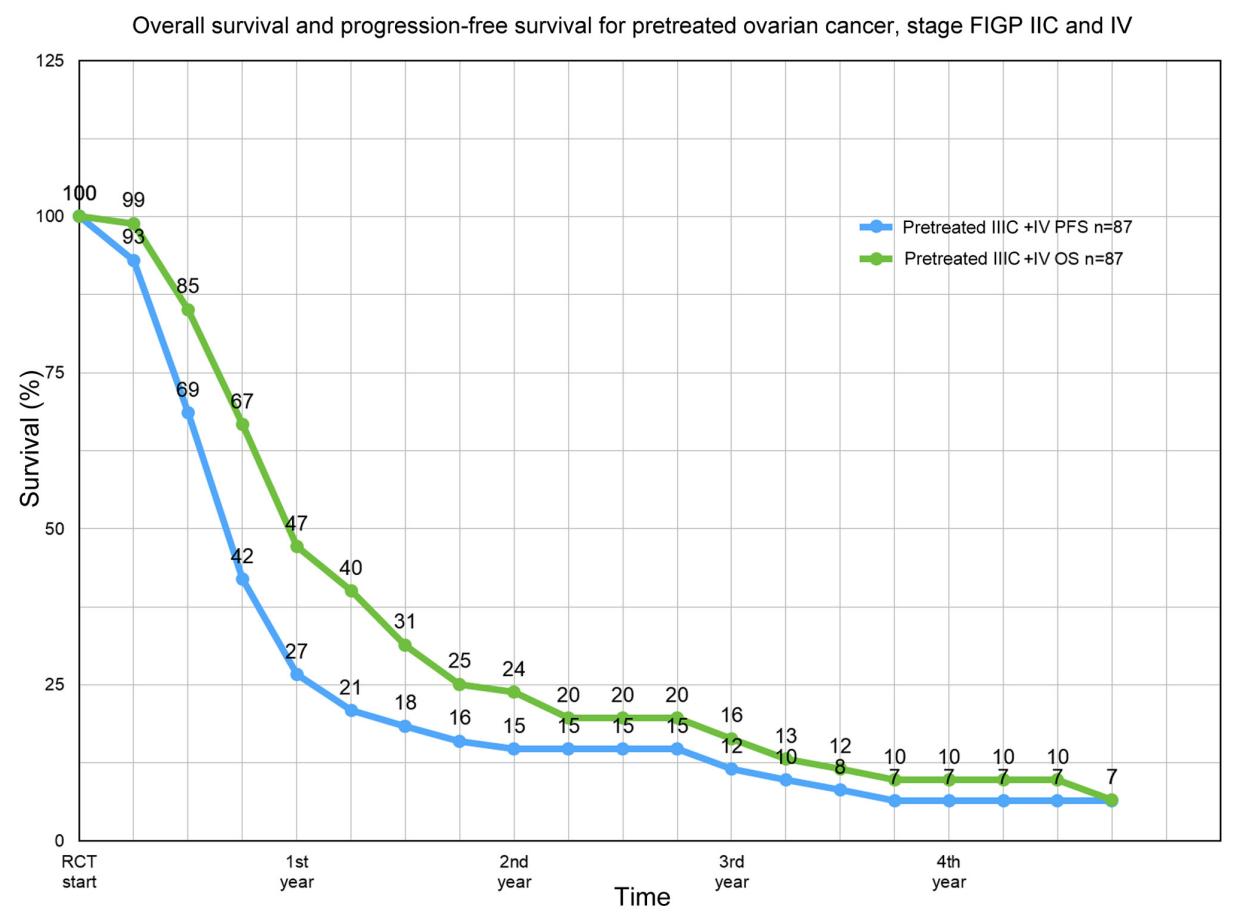

Figure 2. PFS and OS of all pretreated patients $(\mathrm{n}=87)$ in FIGO stage IIIC and IV. PFS, progression-free survival; OS, overall survival; FIGO, Fédération Internationale de Gynécologie et d'Obstétrique; RCT, regional chemotherapy.

within a few days. The syndrome occurs in $10-15 \%$ of patients, accompanied by fever and lassitude (Table V). In general, the performance of patients improves after perfusion therapy with chemofiltration from therapy to therapy (29).

\section{Discussion}

Ovarian cancer is the leading cause of death, and cure rates between $12-14 \%$ have changed little over the past few decades. Debulking operations in terms of complete cytoreduction and platinum-based chemotherapy are considered the cornerstones of current therapy.

On the remaining options, an increase in dose in systemic chemotherapy is limited by the increasing toxicity $(8,9)$. Because of the angiogenic properties of ovarian cancer, targeted therapies appeared to be a logical and generally accepted option (21). On the one hand, they were complicated by not inconsiderable collateral damage such as perforations in the intestine due to microcirculation disorders in the intestinal wall, bleedings, proteinuria and high blood pressure. On the other hand, the clinical results with bevacizumab were not necessarily convincing; the median survival of 6.9 months in a group of 32 multiple chemically pretreated patients after treatment with bevacizumab was rated as good, but did not reach the 11.3 months of a comparable group after isolated perfusion therapy which corresponds to an increase of over $60 \%$ (23). Due to the large difference in survival, this may indicate a trend towards isolated perfusion, but is of limited importance due to the small number of cases, not necessarily comparable patient groups and the lack of randomization. In spite of all restrictions, in addition to the good survival times, the minor side effects with mostly rapid improvement in the quality of life through 'segmental' limited chemotherapy with subsequent detoxification are of primary importance. The basic prerequisite for any cancer treatment should be the prolongation of life while maintaining and if possible improving the quality of life. No other fundamental necessity for any treatment to be recommended should actually apply (24). Side effects scales in patients who were progressive after systemic therapies of different tumor entities and then received regional chemotherapy (RCT) showed significantly fewer side effects and better quality of life after regional chemotherapy (29). The reduction or removal of all tumor masses is a prerequisite for thorough treatment of advanced ovarian cancer. Debulking 


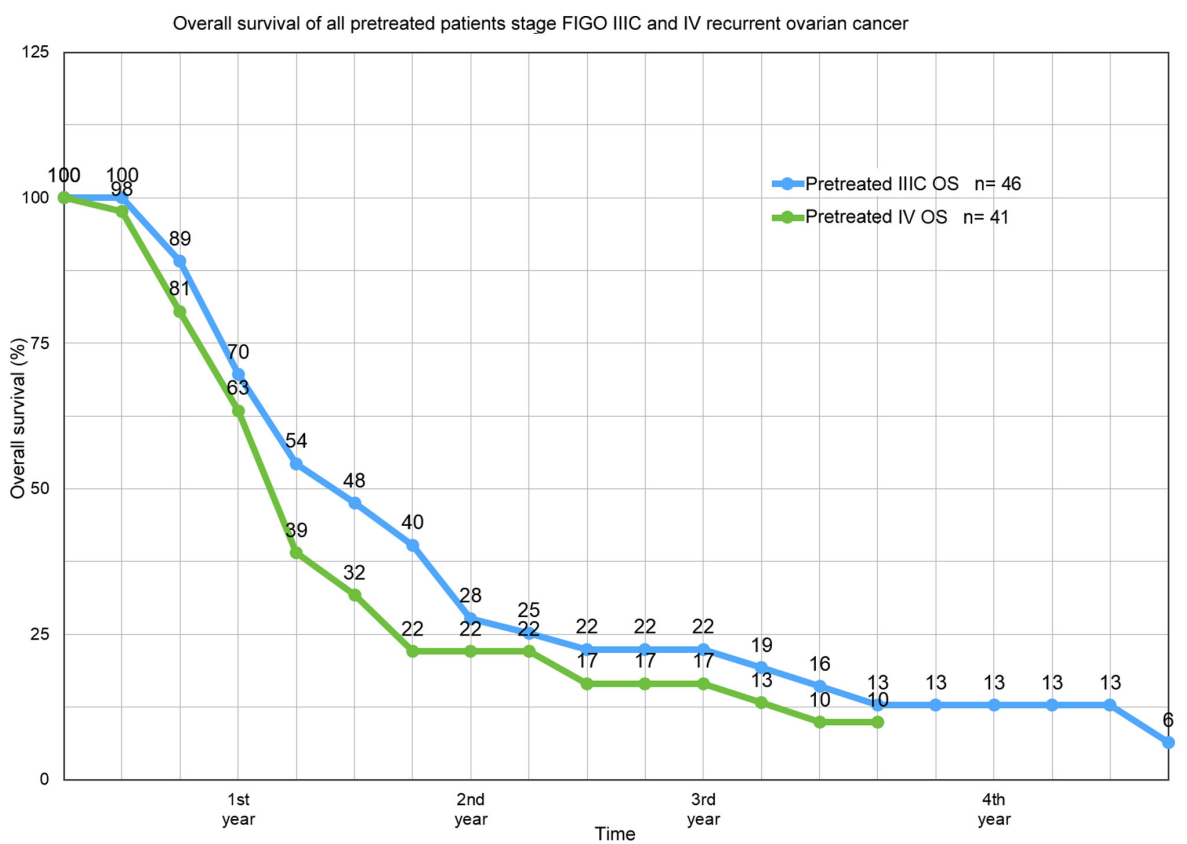

Figure 3. Overall survival of all pretreated patients in FIGO stage IIIC and IV. OS, overall survival; FIGO, Fédération Internationale de Gynécologie et d'Obstétrique.

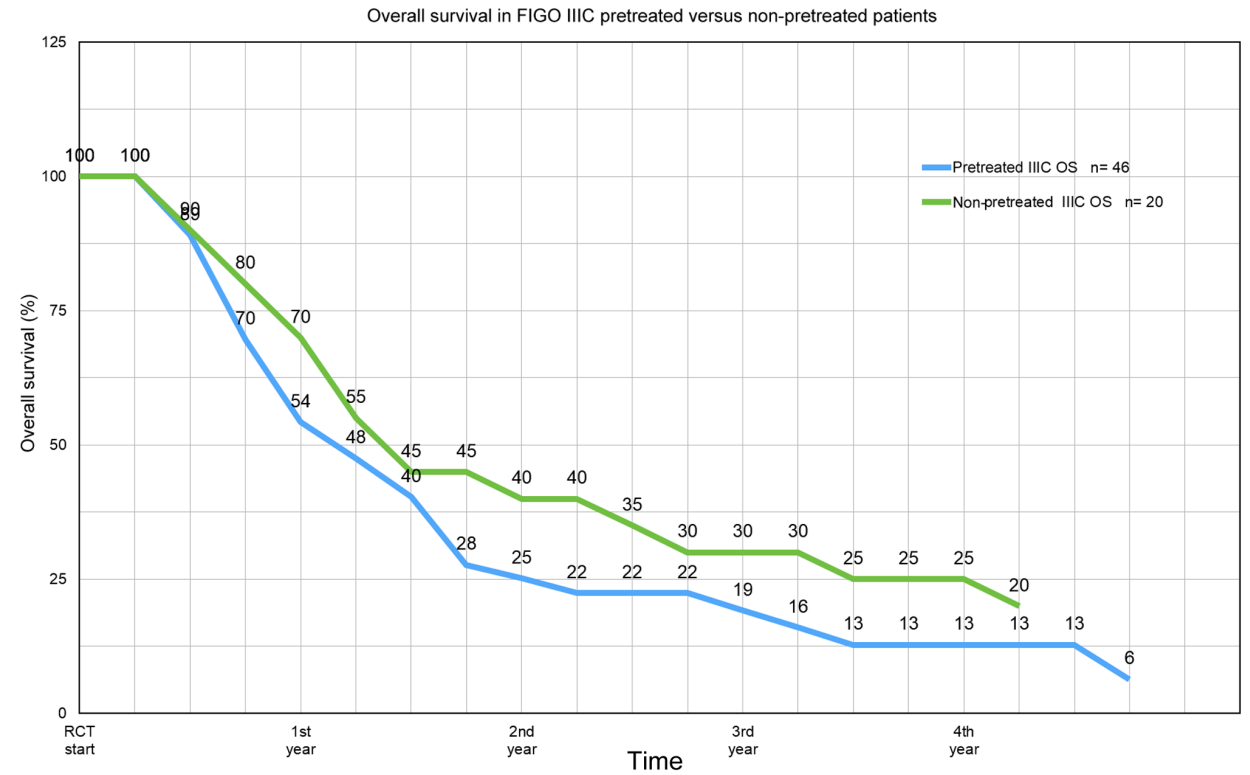

Figure 4. Overall survival in FIGO stage IIIC pretreated vs. non-pretreated patients. OS, overall survival; FIGO, Fédération Internationale de Gynécologie et d'Obstétrique; RCT, regional chemotherapy.

Table V. Toxicity profile after isolated hypoxic abdominal perfusion with cisplatin, adriamycin and mitomycin for advanced ovarian cancer.

\begin{tabular}{lc}
\hline Adverse event & Extent \\
\hline Bone marrow suppression & WHO grade I/II \\
Fatigue syndrome & $15-20 \%$ \\
Transient elevation of creatinin & $15 \%$ \\
Neutropenic fever & $0 \%$ \\
Hand-foot-syndrome & $0 \%$ \\
\hline
\end{tabular}

WHO, World Health Organization. surgery with no or less than $1 \mathrm{~cm}$ residual tumor is also considered a decisive factor for the long-term prognosis. Basically, the aim is to achieve this, but the greater the tumor mass, the more difficult it is to achieve.

Primary surgery for complete cytoreduction is not possible in advanced stage IV ovarian cancers; these patients can only be treated with chemotherapy.

The DESKTOP III study, comparing chemotherapy and tumor debulking surgery vs. chemotherapy alone was the first prospectively randomized trial showing an overall survival benefit of debulking surgery in recurrent ovarian cancer (30). In other studies with secondary cytoreduction combined with platinum-based chemotherapy in relapsed 
ovarian cancer, no differences were found in progression-free survival and overall survival, which may be due to different clinical expertise in the radicality of cytoreduction, but also in biological criteria and medication, including the role of bevacizumab in combination therapy is still unclear (31-34). The preoperative tumor load also influences survival, just as solitary recurrent disease is associated with a much better life expectancy (35).

HIPEC pursues the purpose of increased exposure to all peritoneal surfaces after debulking surgery and the best results are expected after debulking to zero or at least less than $1 \mathrm{~cm}$ residual disease because the depth of penetration of cytostatics under hyperthermic peritoneal irrigation is at most $2 \mathrm{~mm}$ (36). Although survival benefits have been shown in randomized studies $(4,18,19)$, the HIPEC procedure is not regarded as the standard of care for first-line therapy of ovarian cancer, not least because of its high toxicity (37-39).

On the other hand, novel methodologies are under investigation, such as PIPAC, pressurized intraperitoneal aerosol chemotherapy (40) and precision chemotherapy using liquid biopsies for chemosensitivity and tumors gene expression assays (41).

The goal of all efforts in the treatment of ovarian cancer, and especially advanced ovarian cancer, is to increase the efficiency of the therapy used without affecting the quality of life due to unacceptable toxicity. It is a well-known rule that a higher local active drug concentration causes a better response. The limiting factor in higher exposure to cytostatics that may be effective is toxicity. With high-dose therapy limited to one region of the body only (28), the tumor can be permanently damaged with good long-term results. A further prolongation of progression-free and overall survival after initial isolated perfusion according to recent data (42-44) might be maintenance therapy with PARP-inhibitors.

Hypoxic abdominal perfusion with chemofiltration on the other hand, is relatively uncomplicated with some vascular surgery experience (28), without the need for follow-up treatment in an intensive care unit. Patients report little or very rarely about relevant side effects, while a decrease in tumor markers and stressful symptoms such as ascites or general discomfort is observed very often. The most striking feature of the isolated perfusion therapy is the high effectiveness with quick onset of tumor response with hardly any side effects and preserved, often improved quality of life.

\section{Acknowledgements}

The authors wish to acknowledge Mr. Giuseppe Zavattieri (Department for Surgical Oncology, Medias Klinikum Burghausen, Burghausen, Germany) for his help and assistance in preparing the manuscript and statistics used in this report.

\section{Funding}

No funding was received.

\section{Availability of data and materials}

The datasets used and/or analyzed during the current study are available from the corresponding author on reasonable request.

\section{Authors' contributions}

KRA, SG and KA conceived the study. KRA and SG developed the methodology and assessed the authenticity of the data. KRA, SG and KA validated the data. KRA and KA performed formal analysis. KRA and SG performed the investigation. KRA and KA provided resources. KRA, SG and KA curated the data. KRA wrote the original draft. KRA and KA reviewed and edited the manuscript. KRA was involved in visualization. KRA supervised the study. KRA was responsible for project administration. All authors read and approved the final manuscript.

\section{Ethics approval and consent to participate}

Investigations were performed in compliance with the principles of good clinical practice outlined in the Declaration of Helsinki and federal guidelines, and had approval by the Medias Institutional Review Committee (permit number MIRB20200515; Burghausen, Germany). Written informed consent was obtained from each participant or participant's guardian.

\section{Patient consent for publication}

Consent for publication was obtained from any individual person whose data are included in this manuscript.

\section{Competing interests}

The authors declare that they have no competing interests.

\section{References}

1. Gourley C and Bookman MA: Evolving concepts in the management of newly diagnosed epithelial ovarian cancer. J Clin Oncol 37: 2386-2398, 2019.

2. MeyerLA,Cronin AM,SunCC,BixelK,Bookman MA,Cristea MC, Griggs JJ, Levenback CF, Burger RA, Mantia-Smaldone G, et al: Use and effectiveness of neoadjuvant chemotherapy for treatment of ovarian cancer. J Clin Oncol 34: 3854-3863, 2016.

3. Vergote I, Tropé CG, Amant F, Kristensen GB, Ehlen T, Johnson N, Verheijen RH, van der Burg ME, Lacave AJ, Panici PB, et al: Neoadjuvant chemotherapy or primary surgery in Stage IIIC or IV ovarian cancer. N Engl J Med 363: 943-953, 2010.

4. Vergote I, Van Nieuwenhuysen E and Vanderstichele A: How to select neoadjuvant chemotherapy or primary debulking surgery in patients with Stage IIIC or IV ovarian carcinoma. J Clin Oncol 34: 3827-3828, 2016.

5. Gore ME, Fryatt I and Wiltshaw E: Treatment of relapsed carcinoma of the ovary with cisplatin or carboplatin following initial treatment with these compounds. Gynecol Oncol 36: 207-211, 1990.

6. Markman M, Rothman R, Hakes T, Reichman B, Hoskins W, Rubin S, Jones W, Almadrones L and Lewis JL Jr: Second-line platinum therapy in patients with ovarian cancer previously treated with cisplatin. J Clin Oncol 9: 389-393, 1991.

7. Ozols RF: Treatment of recurrent ovarian cancer: Increasing options-'recurrent' results. J Clin Oncol 15: 2177-2180, 1997.

8. Gore M, Mainwaring P, A'Hern R, MacFarlane V, Slevin M, Harper P, Osborne R, Mansi J, Blake P, Wiltshaw E and Shepherd J: Randomized trial of dose-intensity with single-agent carboplatin in patients with epithelial ovarian cancer. London Gynaecological Oncology Group. J Clin Oncol 16: 2426-2434, 1998.

9. Jodrell DI, Egorin MJ, Canetta RM, Langenberg P, Goldbloom EP, Burroughs JN, Goodlow JL, Tan S and Wiltshaw E: Relationships between carboplatin exposure and tumor response and toxicity in patients with ovarian cancer. J Clin Oncol 10: 520-528, 1992.

10. McGuire WP, Hoskins WJ, Brady MF, Homesley HD, Creasman WT, Berman ML, Ball H, Berek JS and Woodward J: Assessment of dose-intensive therapy in suboptimally debulked ovarian cancer: A Gynecologic Oncology Group study. J Clin Oncol 13: 1589-1599, 1995. 
11. Markman M, Liu PY, Moon J, Monk BJ, Copeland L, Wilczynski S and Alberts D: Impact on survival of 12 versus 3 monthly cycles of paclitaxel $\left(175 \mathrm{mg} / \mathrm{m}^{2}\right)$ administered to patients with advanced ovarian cancer who attained a complete response to primary platinum-paclitaxel: Follow-up of a Southwest Oncology Group and Gynecologic Oncology Group phase 3 trial. Gynecol Oncol 114: 195-198, 2009.

12. Omura GA, Brady MF, Look KY, Averette HE, Delmore JE, Long HJ, Wadler S, Spiegel G and Arbuck SG: Phase III trial of paclitaxel at two dose levels, the higher dose accompanied by filgrastim at two dose levels in platinum-pretreated epithelial ovarian cancer: An intergroup study. J Clin Oncol 21: 2843-2848, 2003.

13. Thigpen JT: Dose-intensity in ovarian carcinoma: Hold, enough? J Clin Oncol 15: 1291-1293, 1997.

14. Grénman S, Wiklund T, Jalkanen J, Kuoppala T, Mäenpää J, Kuronen A, Leminen A, Puistola U, Vuolo-Merilä P, Salmi T, et al: A randomised phase III study comparing high-dose chemotherapy to conventionally dosed chemotherapy for stage III ovarian cancer: The Finnish Ovarian (FINOVA) study. Eur J Cancer 42: 2196-2199, 2006.

15. Möbus V, Wandt H, Frickhofen N, Bengala C, Champion K, Kimmig R, Ostermann H, Hinke A and Ledermann JA AGO-Ovar/AIO; EBMT: Phase III trial of high-dose sequential chemotherapy with peripheral blood stem cell support compared with standard dose chemotherapy for first-line treatment of advanced ovarian cancer: Intergroup trial of the AGO-Ovar/AIO and EBMT. J Clin Oncol 25: 4187-4193, 2007.

16. Fung MF, Johnston ME, Eisenhauer EA, Elit L, Hirte HW and Rosen B; Cancer Care Ontario Practice Guidelines Initiative Gynecology Disease Site Group: Chemotherapy for recurrent epithelial ovarian cancer previously treated with platinum-a systematic review of the evidence from randomized trials. Eur J Gynaec Oncol 23: 104-110, 2002.

17. Du Bois A, Weber B, Rochon J, Meier W, Goupil A, Olbricht S, Barats JC, Kuhn W, Orfeuvre H, Wagner U, et al: Addition of epirubicin as a third drug to Carboplatin-paclitaxel in first-line treatment of advanced ovarian cancer: A prospectively randomized gynecologic cancer intergroup trial by the Arbeitsgemeinschaft Gynaekologische Onkologie Ovarian Cancer Study Group and the Groupe d'Investigateurs Nationaux pour l'Etude des Cancers Ovariens. J Clin Oncol 24: 1127-1135, 2006.

18. Spiliotis J, Halkia E, Lianos E, Kalantzi N, Grivas A, Efstathiou E and Giassas S: Cytoreductive surgery and HIPEC in recurrent epithelial ovarian cancer: A prospective randomized phase III study. Ann Surg Oncol 22: 1570-1575, 2015.

19. Van Driel WJ, Koole SN, Sikorska K, Schagen van Leeuwen JH, Schreuder HW, Hermans RH, de Hingh IH, van der Velden J, Arts HJ, Massuger LF, et al: Hyperthermic intraperitoneal chemotherapy in ovarian cancer. N Engl J Med 378: 230-240, 2018.

20. Armstrong DK, Bundy B, Wenzel L, Huang HQ, Baergen R, Lele S, Copeland LJ, Walker JL and Burger RA; Gynecologic Oncology Group: Intraperitoneal cisplatin and paclitaxel in ovarian cancer. N Engl J Med 354: 34-43, 2006.

21. Yi S, Zeng L, Kuan Y, Cao Z, Zheng C, Zhang Y, Liao M and Yang L: Antiangiogenic drugs used with chemotherapy for patients with recurrent ovarian cancer: A meta-analysis. Onco Targets and Therapy 10: 973-984, 2017.

22. Stone RL, Sood AK and Coleman RL: Collateral damage: Toxic effects of targeted antiangiogenic therapies in ovarian cancer. Lancet Oncol 11: 465-475, 2010

23. Monk BJ, Han E, Joseph-Cowen CA, Pugmire G and Burger RA Salvage bevacizumab-(rhuMABVEGF)-based therapy after multiple prior cytotoxic regimens in advanced refractory epithelial ovarian cancer. Gynecol Oncol 102: 140-144, 2006.

24. Cannistra SA: The ethics of early stopping rules: Who is protecting whom? J Clin Oncol 22: 1542-1545, 2004.

25. Aigner KR and Gailhofer S: High dose MMC: Aortic stopflow infusion (ASI) with versus without chemofiltration: A comparison of toxic side effects (abstract). Reg Cancer Treat 6 (Suppl 1): S3, 1993.

26. Aigner KR, Tonn JC, Hechtel R and Seuffer R: Die intraarterielle Zytostatikatherapie mit venöser Filtration im halboffenen System. Onkologie 6: 74-76, 1983.

27. Teicher BA, Lazo JS and Sartorelli A: Classification of antineoplastic agents by their selective toxicities toward oxygenated and hypoxic tumor cells. Cancer Res 41: 73-81, 1981.

28. Aigner KR, Selak E, Gailhofer S and Aigner K: Hypoxic Isolated Abdominal Perfusion (HAP) chemotherapy for non-operable advanced staged ovarian cancer with peritoneal carcinosis: An experience in 45 platinum-refractory ovarian cancer patients. Indian J Surg Oncol 10: 506-514, 2019.
29. Aigner KR and Knapp N: Toxicity Profiles with Systemic vs. Regional Chemotherapy. In: Induction Chemotherapy-Systemic and Locoregional. 2nd edition. KR Aigner and FO Stephens (eds). Springer Verlag Berlin, pp497-506, 2016.

30. Du Bois A, Vergote I, Ferron G, Reuss A, Meier W, Greggi S, Jensen PT, Selle F, Guyon F, Pomel C, et al: Randomized controlled phase III study evaluating the impact of secondary cytoreductive surgery in recurrent ovarian cancer: AGO DESKTOP III/ENGOT ov20. J Clin Oncol 35: 5501, 2017.

31. Shanghai Gynecologic Oncology Group. Surgery or Chemotherapy in Recurrent Ovarian Cancer (SOC 1 Trial). National Library of Medicine, Bethesda, MD, 2018. Available from: www.clinicaltrials.gov/ct2/show/record/NCT01611766.

32. Zang $\mathrm{R}$ and Zhu J: Which patients benefit from secondary cytoreductive surgery in recurrent ovarian cancer? J Gynecol Oncol 30: e116, 2019.

33. Coleman RL, Enserro D, Spirtos N, Herzog TJ, Sabbatini P, Armstrong DK, Kim B, Fujiwara K, Walker JL, Flynn PJ, et al: A phase III randomized controlled trial of secondary surgical cytoreduction (SSC) followed by platinum-based combination chemotherapy (PBC), with or without bevacizumab (B) in platinum-sensitive, recurrent ovarian cancer (PSOC): A NRG Oncology/Gynecologic Oncology Group (GOG) study. J Clin Oncol 36: 5501-5501, 2018.

34. Coleman RL, Spirtos NM, Enserro D, Herzog TJ, Sabbatini P, Armstrong DK, Kim JW, Park SY, Kim BG, Nam JH, et al: Secondary surgical cytoreduction for recurrent ovarian cancer: N Engl J Med 381: 1929-1939, 2019.

35. Vargas HA, Burger IA, Goldman DA, Miccò M, Sosa RE, Weber W, Chi DS, Hricak H and Sala E: Volume-based quantitative FDG PET/CT metrics and their association with optimal debulking and progression-free survival in patients with recurrent ovarian cancer undergoing secondary cytoreductive surgery. Eur Radiol 25: 3348-3353, 2015

36. Van de Vaart PJ, van der Vange N, Zoetmulder FA, van Goethem AR, van Tellingen O, ten Bokkel Huinink WW, Beijnen JH, Bartelink H and Begg AC: Intraperitoneal cisplatin with regional hyperthermia in advanced ovarian cancer: Pharmacokinetics and cisplatin-DNA adduct formation in patients and ovarian cancer cell lines. Eur J Cancer 34: 148-154, 1998.

37. Vergote I, Harter P and Chiva L: Is there a role for intraperitoneal chemotherapy, including HIPEC, in the management of ovarian cancer? J Clin Oncol 37: 2420-2423, 2019.

38. Gore M, du Bois A and Vergote I: Intraperitoneal chemotherapy in ovarian cancer remains experimental. J Clin Oncol 24: 4528-4530, 2006

39. Colombo N, Sessa C, du Bois A, Ledermann J, McCluggage WG, McNeish I, Morice P, Pignata S, Ray-Coquard I, Vergote I, et al: ESMO-ESGO Consensus Conference on Ovarian Cancer: Pathology and molecular biology, early and advanced stages, borderline ovarian tumours and recurrent disease. Ann Oncol 30: 672-705, 2019.

40. Tempfer CB, Winnekendonk G, Solass W, Horvat R, Giger-Pabst U, Zieren J, Rezniczek GA and Reymond MA: Pressurized intraperitoneal aerosol chemotherapy in women with recurrent ovarian cancer: A phase 2 study. Gynecol Oncol 137: 223-228, 2015.

41. Guadagni S,Clementi M,Masedu F,Fiorentini G,SartiD,Deraco M, Kusamura S, Papasotiriou I, Apostolou P, Aigner KR, et al: A pilot study of the predictive potential of chemosensitivity and gene expression assays using circulating tumour cells from patients with recurrent ovarian cancer. Int J Mol Sci 21: 4813, 2020.

42. Del Campo JM, Matulonis UA, Malander S, Provencher D, Mahner S, Follana P, Waters J, Berek JS, Woie K, Oza AM, et al: Niraparib maintenance therapy in patients with recurrent ovarian cancer after a partial response to the last platinum-based chemotherapy in the ENGOT-OV16/NOVA Trial. J Clin Oncol 37: 2968-2973, 2019.

43. Poveda A: Final overall survival (OS) results from SOLO2/ ENGOT-ov21: A phase III trial assessing maintenance olaparib in patients (pts) with platinum-sensitive, relapsed ovarian cancer and a BRCA mutation. Presented at: 2020 ASCO Virtual Scientific Program; Abstract 6002, May 12, 2020.

44. Moore K, Colombo N, Scambia G, Kim BG, Oaknin A, Friedlander M,Lisyanskaya A, Floquet A, Leary A, Sonke GS, et al: Maintenance Olaparib in patients with newly diagnosed advanced ovarian cancer. N Engl J Med 379: 2495-2505, 2018.

This work is licensed under a Creative Commons Attribution-NonCommercial-NoDerivatives 4.0 International (CC BY-NC-ND 4.0) License. 